\title{
The Common Language of Sustainable Architecture in Creating New Architectural Spaces
}

\author{
Tayebeh Nazarian \\ Faculty of Architecture \& Urbanism, Imam Khomeini International University, Qazvin, Iran
}

\section{Email address:}

tnazarian@yahoo.com

\section{To cite this article:}

Tayebeh Nazarian. The Common Language of Sustainable Architecture in Creating New Architectural Spaces. International Journal of Science, Technology and Society. Special Issue: Research and Practice in Architecture and Urban Studies in Developing Countries. Vol. 3, No. 2-1, 2015, pp. 47-51. doi: 10.11648/j.ijsts.s.2015030201.20

\begin{abstract}
In the outlook for global environmental, sustainability is defined as a dream of the present-day needs without compromising resources for future generations. Achieving this objective in the international community requires explaining the policies, objectives and strategies that can be achieved through the construction of sustainable human environments. In this context, it is essential to find a common language and means which can create a link between the architecture of buildings and urban spaces around the world. This language can be obtained by analyzing the characteristics and principles of designing of Green architecture, High -Tech architectures and Echo-Tech architecture as the symbols of sustainable architecture and we can see these principles in the construction of new technologies in the world. The purpose of this study is to seek this common language for designing sustainable architectural spaces. The method of this study is based on library studies and descriptive approach. The results of this study were to give the principles, standards and common tools for creating sustainable architecture spaces and to explain the alphabet of this language including modular systems, flexible integrated spaces, using nature in sustainable architecture, green materials, etc.
\end{abstract}

Keywords: Sustainable Architecture, Modular System, Flexibility, Green Materials, Nature

\section{Introduction}

Nowadays, the term of the stability is used to describe the world in which human and natural systems can be combined with each other to survive the distant future. This term by itself has followed concepts such as sustainable development, sustainable environment, sustainable cities and sustainable architecture. Key points in the sustainable design are including low power consumption, high flexibility and high efficiency in the use of resources. Sustainable architecture in order to improve quality of life and sustainable development, while reducing energy consumption and reducing environmental pollution, coordinates its constituent elements in order to achieve sustainable development goals [2].

Design and construction of sustainable man-made spaces in terms of architecture and urbanism can only be achieved worldwide when the principles of sustainable architecture and tools and components as a common language to be used in creating these spaces. The prerequisite to achieve this objective is to recognize the alphabet of designing sustainable architecture and its reflection in the form of new construction.

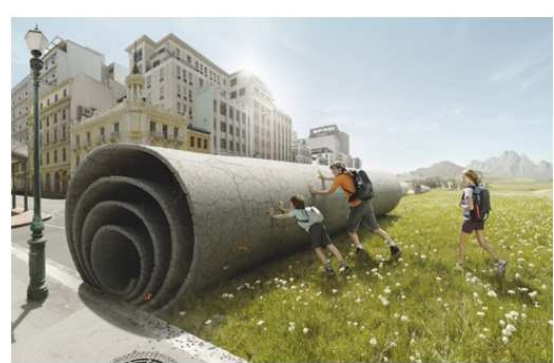

Figure 1. Green Architecture.

\section{Principles of Sustainable Architecture}

Sustainable architecture is the human architecture which its goal is designed to reduce damage to the environment, energy resources and nature. In a general context, we can use sustainable architecture as the means to "create a stable man-made environment" which according to the general definition of Green Architecture, Echo Tech architecture and Organic Tech architecture are the subsets of the sustainable architecture. The architectural trends in content and in form of 
joint manifestations are different. The main objectives of sustainable architecture are:

- Organizing the flexible and multifunctional actions.

- Maximum use of renewable energy.

- No adverse environmental impact on your site of living.

- Use of Climate design.

- Use the native form and in accordance with climatic conditions.

- Improving the quality of life.

\subsection{Green Architecture}

The most basic issues of Green Architecture or the main appearance of sustainable architecture, energy saving, environmental global issues, optimizing production processes and materials are the principals of the local architecture. In the Green Architecture, the constitution should be done in the developed areas and ease of access to public transport, bicycle paths and pedestrian access to basic services should be provided. The intact and pristine areas must be maintained and the buildings must be designed to minimize the environmental pressure. Of other features of Green Architecture are designing of the projects and multipurpose plans, utilization of native vegetation and climate and reconstruction of old buildings. The most important principles of Green Architecture are:

- Reduced use of new resources: reuse of recycled materials.

- Understanding of the environment: climate design.

- Relationship with nature.

- Understand the environmental impacts: assessment of energy consumption, green and recyclable materials, and construction techniques.

- Respect the user's attention to human needs and workforce.

- Creation of a participatory design process.

- Understanding People: Understanding the culture, religion, race, etc.

- Holism: attention to a sustainable urban environment for the design of individual buildings [1].

\subsection{High-Tech Architecture}

Although High-Tech is not a single subset of sustainable architecture, but as the basis and background of Eco-Tech Architecture theories and principles of Modern Architecture and High-Tech are very similar in terms of the principles , but in terms of form are different. Simplicity which is in Modern Architecture is not seen in High - Tech. High-Tech or architecture with advanced technology, seeks to portray the role of technology and industry. A key aspect of High- Tech is:

- Emphasis on industrial and prefabricated components on a regular and adjusted basis.

- Creation of a unified space through the use of prefabricated elements Space Frame.

- The use of glass walls reliable and resilient integrated in the outer wall of the building.

- The use of light steel components and composite structures.

- Designing the roof of the building.

\subsection{Eco-Tech Architecture}

Eco-Tech Architecture (Ecology + Technology) is not a formal style but is profound in its implications in combination of man, nature and architecture. In the Eco-Tech Architecture, building is working as part of the surrounding nature and should act as part of the ecosystem. Eco-Tech Architecture approach have shaped based on quality, attention to and concern for the environment.

The main objectives of Eco-Tech Architecture are to achieve high standards of quality, safety and comfort. This quality, regardless of the nature, do not provide maximum use of natural elements (sun, wind, water, groundwater, plants), appropriate lightening of spaces, air conditioning, stability and durability of the building. In this practice of architecture, technology parallel to a nature is used to exploit environmental resources. Therefore High-Tech and Eco-Tech Architecture are the complement of each other. The principals of architectural designing of High-Tech and eco -tech practices are:

- Optimism in science and scientific and technical progress.

- Displaying technology.

- Displaying the manufacturing process.

- Transparent, layer and monitoring of construction.

- Displaying the structure and components of the building facade.

- The use of bright and simple colors.

- Use as a decorative building structure.

- Using tensile elements of style.

- Remove the server from the drop-service.

- The designing of the roof as a fifth facade of the building.

According to studies done on the general principles of sustainable architecture, Green Architecture, High-Tech and Eco - Tech Architecture and whole structure of constructed buildings can be the common courses of these principles. This common course represents the basic elements of designing the sustainable architectural spaces that can be used as a common language between the spaces of sustainable architecture worldwide. Although the difference in performance, climate, culture, ecology, economy and austainable architectural design can vary in form, but the meaning behind it is ineffective.

\section{Flexibility}

Flexibility is the capability of changing in the constructed space or the capability of changing in it to achieve new needs and uses. In other words, when we have a physical system without changing its basic elements in the original or derived, allowing the space to suit the needs exist, we have flexibility. Since the elements of space are defining that space, to have more flexible spaces, these factors should be flexible.

Flexibility is related to social performance of psychological, economic factors and over time, with changes in the urban and 
rural, family, and daily and seasonal habits of people and changes in the activity of the population becomes the most important principle. So the physical space of the building must conform to the cultural, natural and man-made environment, and environmental, economic, social, political and community livelihoods.

Flexibility will be in three species: diversity, versatility and variability. Variety of space to have the concept of multi-functional space fits the needs of the possibility of changing space. Adaptability is the functional flexibility and performance of a space in which mobility across sectors and regions is proportional to the time and season [9].

Movable and semi-fixed elements and foldable furniture with the methods of transportation of decoration, land use changes, the use of multi-purpose spaces and movable partitions are adaptation aspects of space.

Variability is the structural flexibility and structural and special framework which can alter the spatial and functional space for other sectors.

The most important feature of flexible architecture includes:

- Ability to use a longer time.

- Compliance with the intervention of the user experience.

- Benefits of technical innovation.

- Economic and ecological sustainability.

- Reuse of all or part of the structure and components of a building.

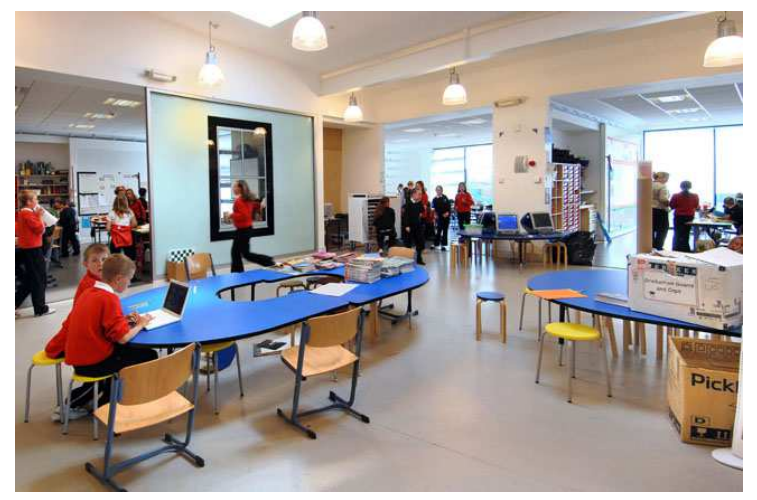

Figure 2. The flexible designing of open planes.

The flexible architecture includes buildings that are designed to respond changings of their lives. The idea of technology for flexible buildings made possible the maintenance of the building and applying the necessary changes without the high cost of implementation. For this purpose, layers of building in sustainable architecture consists of mass (structural and bearing shells), service sector (pipe, duct, cable, elevators, escalators, etc.), stage (partitions, ceilings, plastering) and device (for furniture moving, etc.) separately and with the opportunity to enhance compatibility with the designing life. Also in modern construction methods, sustainable architecture, the use of flexible structures has caused the structural components to easily being replaceable, reusable and recyclable.

\section{The Modular System}

One of the tools for sustainable architecture is the use of industrial systems of building to reduce manual work at the site, increase speed manufacturing processes, control of the quality components. The possibility of producing the same product series provides industrial and building automation using a variety of products in certain areas Furthermore, the high degree of standardization and repetition are made.

Modular architecture is the strategy for greater efficiency and flexibility of the building. In modulation, organization and assembly of modular components based on geometrical laws and the building is done and the location is specified as a basic element which is the basic structure of the classification of geometric forms.

Modular systems are targeted systems which in them we have harmony of components and reproducibility. The process followed during the production, manufacturing and debugging in there. To determine the modulus size, dimensions and functional spaces include various aspects of performance, the media and communication spaces are studied and the optimum size based on climate, standards and optimal price is determined. The separation of structural elements including walls, ceiling and wall pieces, and stair openings, etc. are studied. Outcome of study is to determine the cause of dimensional moduli spaces of stable architecture. The modules can applies in small spaces, combining different spaces, combining building blocks, urbanism and building materials and systems [11].

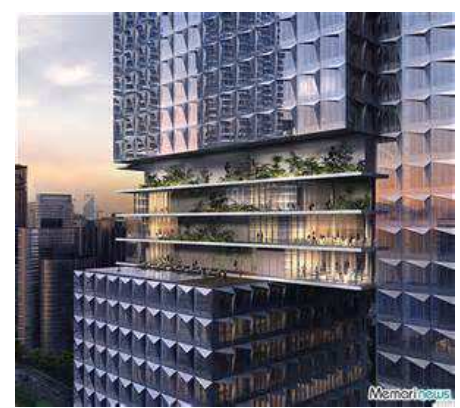

Figure 3. An example of the modular System.

The most important advantages of the modular system in designing of sustainable architecture are:

- The division of tasks in parallel product development.

- Industrial and reduce production costs and increase production volume.

- Possibility of installation.

- Maintenance.

- Upgrading and modernization.

- Diversification of product.

- Recycling and reuse.

- Ability to customize the product [10].

\section{Green Materials}

Green buildings include:

- Energy and resource efficient. 
- Non-wasteful and non-polluting.

- Sustainable design that helps minimizes broad environmental impacts (e.g. ozone depletion).

- Highly flexible and adaptable for long-term functionality.

- Easy to operate and maintain (lower running costs).

- Supportive of the productivity and well-being of the occupants [3].

In the flexible designing of sustainable architecture and spaces of modular systems, the use of green building materials is of particular importance. Green materials are the materials in which the material is said to be renewable rather than non-renewable materials or materials that are made from recycled materials or materials that are made from nature and returns to nature. The use of green materials building is done to increase the efficiency of resource use and conservation of natural resources, public health and the health of the residents of the building, environmental and public interest.

Green materials bring efficiency by increasing the efficiency of manufacturing processes, recycling and reduction or elimination of toxic components, thereby reducing the adverse effects of short-term and long-term environmental and economic sustainability in the industry. The combined use of raw materials and recycled materials can increase the adaptability of the environment.

The impact of materials processing can be global and have long-term consequences. So the selection of materials is particularly important and using these materials is, by definition, sustainable:

- Use materials made from renewable resources.

- Use materials harvested or extracted without causing ecological damage.

- Use recycled materials.

- Use materials with long life and low maintenance [5].

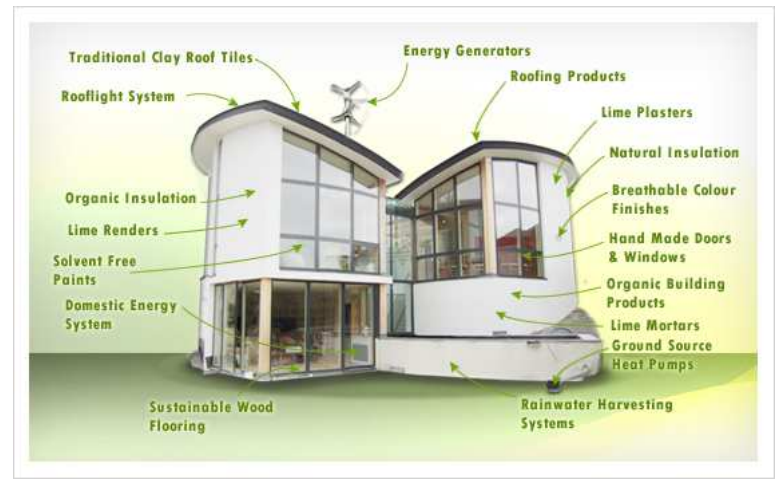

Figure 4. Using of green materials in sustainable designing.

The most important selection criteria for green building materials are:

- Resource efficiency: using reconstructed or re-produced materials, materials made from recycled materials, recycling or reuse of materials, materials made from waste.

- Durable materials made from renewable resources.

- Reduce the use of other substances (paints, coatings, etc.).
- Energy: energy efficiency during use, accurate energy consumption (using automatic sensors), low energy consumption of the production process.

- Water efficiency, water consumption, water consumption during production [7].

In Green Architecture, we used from environment-friendly materials in the structure, hard work and joinery and other building components. Use of materials found in the environment, local materials, building materials or waste products derived from substances back into the cycle of nature and no polluting emissions are other aspects of the use of green materials in the construction of the new architecture. Also in line with the objectives of sustainable architecture, the use of ozone depleting chemicals avoids in the mechanical and plant equipment and insulation.

\section{Atrium}

The main cause of the ecological relationship between sustainable buildings and environments is an intermediate space named Atrium. This space relates the building and the city, stably and defines their boundaries. Atrium space in buildings with sustainable architecture, natural light and protected space from the wind and rain, as well as facilitating access, the existence of inhabitants and tropical trees and ground cover can be generated for the residents of the building. This space acts as a focus of visual and functional space for circulation, sitting, talking and playing, interaction, integration, and learning. The space is the ecological balance between the building and the nature.

Although the atrium decreases the direct Curran and received light from the windows between the two buildings, but by generally comparing the comfort of the two conditions, it could be seen that the differences are caused more by the personal feelings, and an appropriate and uniform distribution of temperature, humidity, and ventilation in all the spaces overlooking the atrium, led to public satisfaction [4].

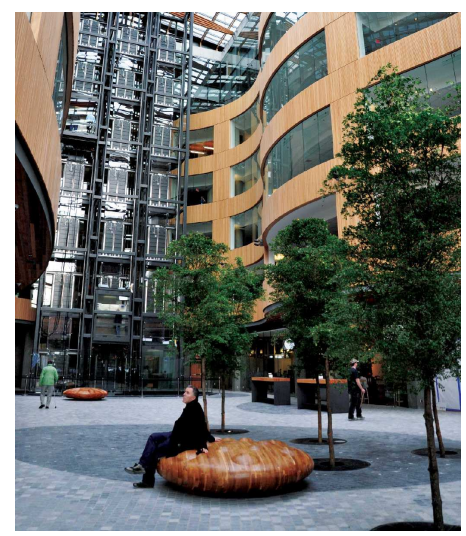

Figure 5. Atrium in Sustainable Architecture.

Atrium reinforces the flexibility of the building as a microclimate, with respect to fluctuations in temperature, humidity and air flow and prevents heat loss considerably [8]. In these environments, the use of climatic factors with equipment like air vent, mirrors reflecting smart shell, 
greenhouses, glass stairs and heat exchange take place and the shape of building designed due to the angle of the sunshine and the wind in different seasons. The most important tools in sustainable architecture in completing Atriums are photovoltaic solar cells, smart windows, air conditioning, fuel and renewable biogas to generate electricity without pollution.

So Atrium or central skylight, one of the most distinctive and identity of the spaces used in the past, especially in Modern Architecture, beyond the internal lighting and access which can be considered a symbol of sustainable architecture in new construction .

\section{Discussion and Conclusion}

This developing approach of sustainable architecture in the world is the main factor to know the principles and standards of the genre and its related manufacturing technologies.

Since in the architectural designing of each space exist three categories of meaning, form and function, understanding the concepts and principles of light as the common language of designers and architects in creating sustainable environments is essential. This common language can be the linking structures that are formed adjacent to each other and achieving sustainable cities, sustainable environment and provide sustainable development.

This the concepts is consistent with the function of space and the use of tools, technologies, construction and building design technology provides a stable form. Flexibility of space, the use of modular systems, the use of green materials and making the building communication with nature by creating an atmosphere of Atrium in sustainable architecture are most important factors in designing sustainable space. Each of these concepts in order to find out uses construction of new technologies in different ways so that they can seek help from their emergence. Identifying strategies to achieve these concepts and their application in the design of sustainable human environments would lead to making something that requires careful consideration of tools, systems, new construction, materials, heating and cooling systems.

\section{References}

[1] J. Asadi, "Sustainable Architecture (Green Architecture)," Young Architects Forum, 2009.

[2] J. Gorgi Mahlabani, "Sustainable Architecture and It's Criticism in Environment Area," Scientific - Research Journal, Iranian Scientific Association of Architecture \& Urbanism, Year 1, NO. 1, 2010.

[3] S. C. M. Hui, "Principles of Sustainable Building," Guest Lecture to HKU Department of Architecture, Mar 2012.

[4] M. Kazemzadeh, F. Sheikh Asadi, "The New Attention to Atrium for Creating Sustainable Townscape," Journal of Civil Engineering and Urbanism, Vol 4, 2014.

[5] J. Kim, B. Rigdon, "Introduction to Sustainable Design", National Pollution Prevention Center for Higher Education, December 1998.

[6] J. Kim, B. Rigdon, "Qualities, Use, and Examples of Sustainable Building Materials", National Pollution Prevention Center for Higher Education, December 1998.

[7] A. Marandi, M. Parvinzade Gashti, "Environmental Building Materials," Conference of Optimization of Energy Consumption in Buildings, Tehran, Iran, April 2006.

[8] S. M. Mofid Shemirani, H. Madi, "Atrium Symbol of Sustainable architecture", Sixth National Energy Congress, Tehran, Iran, May 2007.

[9] M. Mirzade, "Flexibility in Optimized Housing Design," Young Architects Forum, January 2013.

[10] J. Oovlia, A. Taghdiri, S. Ghanbarzadeh Qummi, "Structural Adjustment Systems for the Building Industry," Scientific Research Journal, Iranian Scientific Association of Architecture \& Urbanism, Year 1, NO. 1, Autumn 2010.

[11] SH. Shokoohi nia, "Massively Modular Housing," Iranian Urbanism Forum, May 1999. 